\title{
Role of Ventrolateral Medulla Catecholamine Cells in Hypothalamic Neuroendocrine Cell Responses to Systemic Hypoxia
}

\author{
D. W. Smith, K. M. Buller, and T. A. Day \\ Department of Physiology and Pharmacology, University of Queensland, QLD 4072, Australia
}

Systemic hypoxia stimulates the release of vasopressin (VP) and adrenocorticotropin hormone (ACTH). To examine the involvement of catecholamine cell groups of the ventrolateral medulla (VLM) in the neuroendocrine responses, we have used the c-fos activity mapping technique to compare the effects of hypoxia on VLM catecholamine cells to those on neurosecretory VP and putative corticotropin releasing factor (CRF) containing cells. A limited degree of catecholamine cell activation was evident at predominantly mid-VLM levels at $12 \%$ oxygen in the inspired air. Further reduction in inpsirate oxygen levels enhanced recruitment of caudally located VLM catecholamine cells considered to form part of the A1 noradrenergic cell group. Threshold for activation of VP and putative CRF cells occurred at the $10 \%$ oxygen level. Unexpectedly, this stimulus also activated neurosecretory oxytocin (OT) cells. With increasing hypoxic severity the number of activated supraoptic VP and OT cells was not significantly different to that observed at the $10 \%$ level. However, paraventricular neuroendocrine responses continued to increase with putative CRF containing cells of the medial parvocellular zone having nearly double the level of activity (as measured by the number of cells within this region displaying Fos-like immunoreactivity; FLI) at $6 \%$ compared to that apparent at the $10 \%$ level of hypoxia. Paraventricular VP cells displaying FLI were also increased at the most severe levels of hypoxia but this effect was much less marked than the medial parvocellular response. Consistent with a role for VLM catecholamine cells in generation of neuroendocrine cell responses to hypoxia, unilateral VLM lesions, restricted to the caudal two thirds of the catecholamine cell column, resulted in significant reductions in the responses of all three cell types. These results, in addition to establishing a role for VLM catecholamine cells in neuroendocrine cell responses to systemic hypoxia, have important general implications for catecholamine cell group involvement in neuroendocrine regulation.

[Key words: systemic hypoxia, ventrolateral medulla catecholamine cell groups, supraoptic and paraventricular nuclei, neuroendocrine cell responses, c-fos]

Received Apr. 11, 1995; revised July 31, 1995; accepted Aug. 4, 1995.

This work was supported by NHMRC and NHF grants. D.W.S. was a recipient of an F. G. Meade scholarship. We thank Dr. D. Pow (VTHRC, University of Queensland) for providing the OT and VP antibodies and M. McKenna and C. Dayas for technical assistance.

Correspondence should be addressed D. W. Smith at the above address

Copyright (C) 1995 Society for Neuroscience $0270-6474 / 95 / 157979-10 \$ 05.00 / 0$
Systemic hypoxia constitutes a challenge to homeostatic mechanisms responsible for the maintenance of adequate tissue oxygen levels and evokes a range of behavioral, autonomic, and endocrine responses. With regard to the latter, hypoxia stimulates the release of both vasopressin (VP) (Forsling and Aziz, 1983; Walker, 1986; Griffen and Raff, 1990; Louwerse et al., 1992) and adrenocorticotropin hormone (ACTH) (Raff and Fagin, 1984; Raff, 1988). These hormonal responses to systemic hypoxia are generally thought to be largely initiated by arterial chemoreceptor activation (Raff et al., 1984; Hanley et al., 1988), but the identity of the relevant central pathways remains unclear.

The nucleus of the solitary tract (NTS) is the primary termination point of chemoreceptor afferents (Kalia and Sullivan, 1982; Housley et al., 1987; Finlay and Katz, 1992) and NTS stimulation excites supraoptic (SON) and paraventricular nucleus (PVN) neurosecretory VP cells (Day et al., 1984; Day and Sibbald, 1989) and putative corticotropin releasing factor (CRF) synthesizing cells of the PVN medial parvocellular (MP) zone (Day et al., 1985; Cunningham et al., 1990; Whitnall, 1993). In the case of the VP cells, at least, this effect has been attributed to a facilitatory input from a column of catecholamine cells in the ventrolateral medulla (VLM) (Day and Sibbald, 1989). Caudally this column contains the Al noradrenergic cell group and rostrally the $\mathrm{C} 1$ adrenergic group, although there is a mid-medullary zone where the groups overlap (Armstrong et al., 1982; Kalia et al., 1985). It is well established that these catecholamine cells project to both the SON and PVN (Tucker et al., 1987; Cunningham and Sawchenko, 1988; Cunningham et al., 1990) and stimulation of VLM regions containing these cells excites both VP neurosecretory and putative CRF cells (Day and Renaud, 1984; Day et al., 1984, 1985; Kannan et al., 1984; Tanaka et al., 1984; Kannan et al., 1987; Saphier and Feldman, 1989), effects that were blocked after neurotoxic lesions of SON and PVN catecholamine terminal plexuses (Day et al., 1985; Saphier and Feldman, 1989).

Certain recent studies support the possibility of a role for VLM catecholamine cells in the hormonal response to systemic hypoxia. Thus, exposure to hypoxic gas mixtures induced c-fos expression in VLM catecholamine cells in conscious rats (Erickson and Millhorn, 1994) and excited SON-projecting VLM cells, presumed to be catecholaminergic, in anaesthetized rabbits (Li et al., 1992). In apparent contrast to the latter study it has been reported that, in the rat, SON-projecting VLM cells are not excited by carotid chemoreceptor activation (Jamieson and Harris, 1989). Nevertheless this same group has also reported that SON VP cell responses to chemoreceptor activation were abolished by VLM lesions (Banks and Harris, 1984).

In the present study we first investigated the role of VLM 


\section{SON}
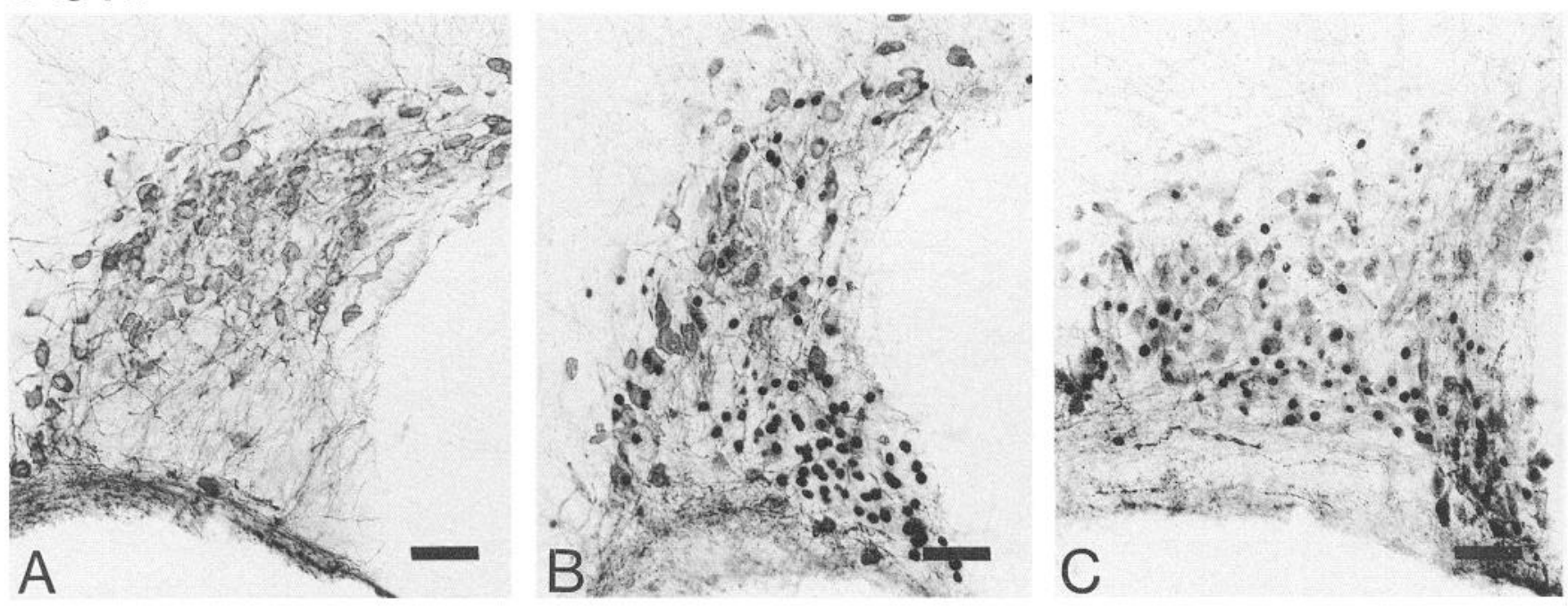

\section{PVN}
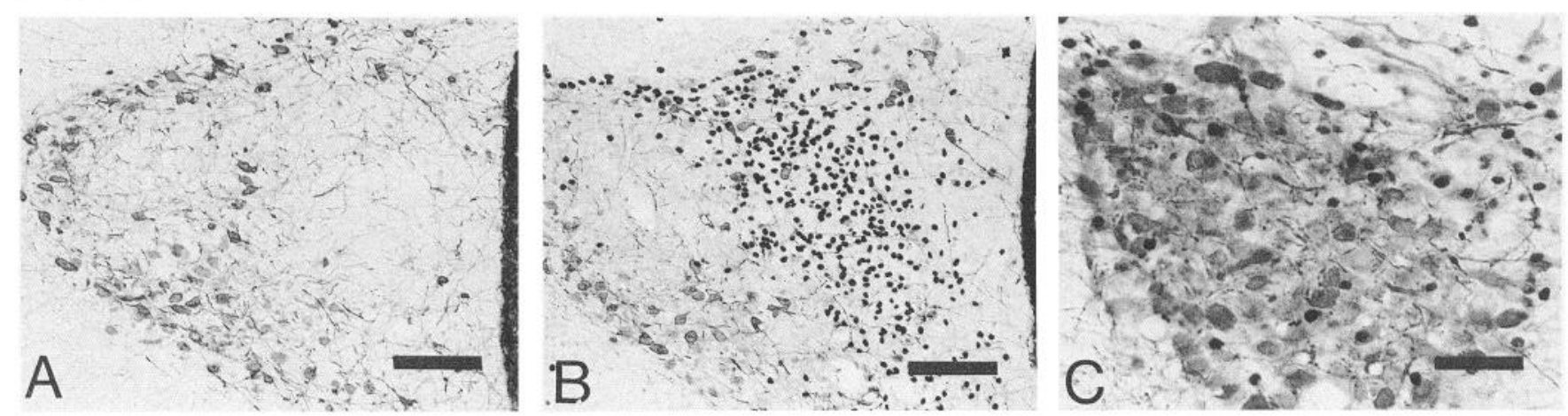

\section{VLM}
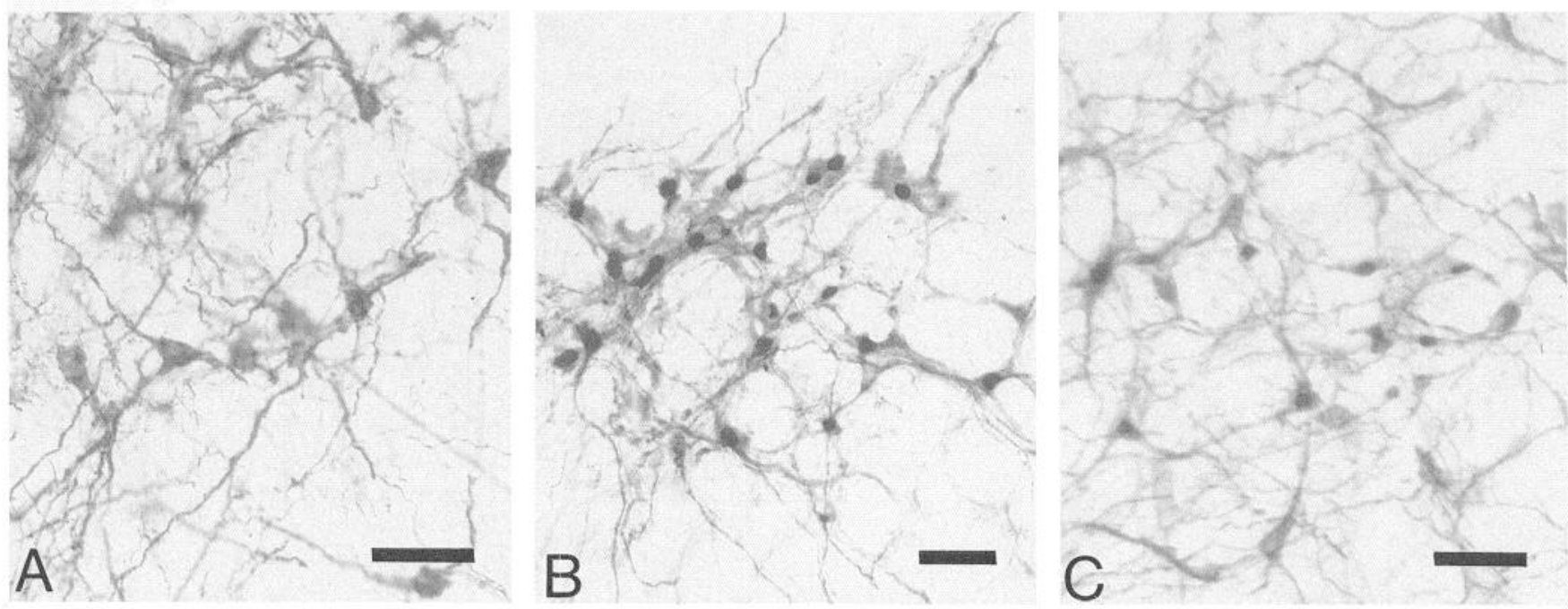

Figure 1. Photomicrographs showing the effects of control and hypoxic conditions on c-fos expression in supraoptic (upper panel) and paraventricular nuclei (middle panel) neuroendocrine cells and VLM catecholamine cells (lower panel). Column A micrographs in all three panels are from control animals and show an almost complete lack of FLI. Columns $B$ and $C$ are from hypoxia animals. SON: $A$, immunolabeled for OT and Fos; 
catecholamine cells in hormonal responses to hypoxia by com paring the responses of hypothalamic neuroendocrine cells and VLM catecholamine cells to graded systemic hypoxia. Because VLM catecholamine cells are a heterogeneous population we have examined their responses at differing rostro-caudal levels throughout the extent of the VLM. Secondly, to directly test VLM catecholamine cell involvement in neuroendocrine cell responses to systemic hypoxia, we examined the effects of VLM lesions on these responses. Lesions were restricted to the more caudal aspects of the VI,M as these have previously been shown to be the primary source of SON and PVN projections, whereas rostral VLM catecholamine cells primarily serve as presympathetic motor neurons (Tucker et al., 1987; Cunningham and Sawchenko, 1988; Morrison et al., 1988). Only the effects of unilateral lesions were tested due to the finding in preliminary studies that bilateral VLM lesions almost invariably resulted in respiratory failure.

\section{Materials and Methods}

Experimental groups. Male Wistar rats $(250-400 \mathrm{~g})$ were divided into five groups. (1) Controls $(n=7)$ : animals were habituated in atmosphere-controlled chambers with free access to water. Chamber air flow was regulated to maintain normal atmospheric $\mathrm{CO}_{2}$ and $\mathrm{O}_{2}$ levels. After $26 \mathrm{hr}$ animals were sacrificed. (2) Hypoxia $(n=40)$ : animals were habituated for $24 \mathrm{hr}$ as above and then, for $2 \mathrm{hr}$ prior to sacrifice, were exposed to one of the following gas mixtures; $\mathrm{O}_{2}: 18,16,14,12,10$, 8 , or $6 \% ; \mathrm{CO}_{2}:<0.4 \%$; balance $\mathrm{N}_{2}$. For all groups $(n=4)$ except $10 \%$ $\mathrm{O}_{2}$ where $(n=16)$. (3) VLM lesions $(n=14)$ : 1 week or more prior to testing animals were anesthetized with pentobarbitone $(50 \mathrm{mg} / \mathrm{kg}$ i.p.), placed in a stereotaxic device and the dorsal surface of the caudal medulla exposed. The excitotoxin ibotenic acid $(250 \mathrm{ng}$ in $50 \mathrm{nl}$ saline) was pressure injected unilaterally into six or seven sites $(300 \mu \mathrm{m}$ intervals) along the VLM catecholamine cell column ( 2.5 caudal to 0.5 $\mathrm{mm}$ rostral to obex, $1.7 \mathrm{~mm}$ lateral to midline, $2.0 \mathrm{~mm}$ below dorsal surface). Once prelesion body weight had been regained (approximately 7 d) three animals were used for lesioned controls and the remaining 11 were used in hypoxia (10\%) experiments as described above. (4) Sham VLM lesions $(n=4)$ : animals were treated identically to the lesion group cxcept that only vehicle (salinc) was injected. These animals were then subjected to hypoxia (10\%) once body weight had recovered. (5) Blood pressure $(n=13)$ : At least 1 week prior to testing animals had their left femoral artery cannulated with heparinized saline $(50 \mathrm{U} / \mathrm{ml})$ filled cannulae, which were exteriorized at the nape of the neck. Animals were habituated in chambers as above, a length of tubing protected by a metal spring was connected to a pressure transducer and the arterial pressure was recorded for $3 \mathrm{hr}, 1 \mathrm{hr}$ prehypoxia, and $2 \mathrm{hr}$ of either 10,8 , or $6 \%$ hypoxia as above.

Processing of tissues. At time of sacrifice animals were deeply anesthetized with pentobarbitone $(50 \mathrm{mg} / \mathrm{kg}$ i.p.) and within $5-10 \mathrm{~min}$ of induction were transcardially perfused with a $2 \%$ sodium nitrite solution immediately followed by $0.1 \mathrm{M}$ phosphate buffered $4 \%$ formaldehyde, $\mathrm{pH}$ 7.4. After a $4 \mathrm{hr}$ postfixation period in the same fixative brains were coronally sectioned at $50 \mu \mathrm{m}$ (brainstem) or $40 \mu \mathrm{m}$ (forebrain) with a vibratome. A one-in-five series of brainstem sections was processed for Fos and TH and two one-in-four series of forebrain sections were processed, one for Fos and OT the other for Fos and VP, using a dual immunoperoxidase technique similar to that previously described (Smith and Day, 1993). Briefly, sections were incubated in Fos antibody (1:15,000 sheep polyclonal, Cambridge Research Biochemicals OA-11824 ) for $48 \mathrm{hr}$ at $4^{\circ} \mathrm{C}$. Sections were then incubated in biotinylated antisheep (1:300, Jackson ImmunoResearch) followed by an avidin-biotinhorseradish peroxidase complex (ABC) solution (Vector Elite Kit) for $2 \mathrm{hr}$ in each. Horseradish peroxidase (HRP) activity was visualized with nickel diaminohenzidine, the reaction heing terminated once optimal intensity was achieved. Appropriate sections were then incubated in either VP (1:1000), OT (1:250; VP/OT-neurophysin directed monoclonals, gifts from D. Pow, University of Queensland) or TH antibody (1: 15000 ; monoclonal, Incstar) for $36 \mathrm{hr}$ at $4^{\circ} \mathrm{C}$ followed by a $2 \mathrm{hr}$ incubation in biotinylated anti-mouse (1:400, Jackson ImmunoResearch) followed by the same ABC and HRP visualization procedure as above but with the nickel omitted. Sections were mounted on chrome-alum subbed slides, dehydrated, xylene cleared, and coverslipped. Staining controls included omission of each step in the procedure. Omission of any antibody or detection system component resulted in absence of label for that antigen.

Analysis. VLM catecholamine cell response analysis consisted of counts of the number of TH-positive cells in the VLM from each of 19 sections spaced at $250 \mu \mathrm{m}$ intervals extending from $2.5 \mathrm{~mm}$ caudal to $2.0 \mathrm{~mm}$ rostral to obex. The percentage of these TH-positive cells colocalizing Fos-like immunoreactivity (FLI) was then determined. In SON, the absolute numbers of VP- and OT-positive cells colocalizing FLI were determined on sections spaced at $160 \mu \mathrm{m}$ intervals. In PVN, Fos positive cells were counted in both the medial parvocellular and magnocellular (neurosecretory cells) regions at two rostro-caudal levels, corresponding to the antero-medial and postero-lateral subdivisions of the posterior magnocellular division (Cunningham and Sawchenko, 1988). At these rostro-caudal levels the MP zone is thought to comprise CRF-containing and autonomic related cells predominantly localized in its dorsal and ventral aspects, respectively (Sawchenko and Swanson, 1982a; Swanson et al., 1983). Comparisons between the graded hypoxia groups were carried out for catecholamine, OT and VP magnocellular and PVN MP cell responses using one way ANOVAs followed by appropriate post-hoc tests to determine the activation threshold group and between group differences for groups displaying suprathreshold levels of activation. Comparisons were also made between suprathreshold hypoxia groups for three zones within the VLM. Zone boundaries were based on the rostro-caudal distribution of the $\mathrm{A} 1$ and $\mathrm{C} 1$ cell groups as determined by quantitative comparisons of TII and PNMT immunolabelled VLM sections from an untreated group of animals (we were unable to achieve dual PNMT/Fos staining of an adequate standard for reliable for quantification). The more rostrally located PNMT-positive cells were not encountered until a level corresponding to $0.5 \mathrm{~mm}$ caudal to obex. Consequently we have classified the zone extending from 0.5 to $2.5 \mathrm{~mm}$ caudal to obex as exclusively A1. From -0.5 to $+0.5 \mathrm{~mm}$ relative to obex there were a greater number of TH-positive than PNMTpositive cells, thus this zone is a mixture of $\mathrm{A} 1$ and $\mathrm{C} 1$ cells. From +0.5 to $+2.0 \mathrm{~mm}$ relative to obex the number of PNMT- and THpositive cells was virtually identical and thus the zone is exclusively $\mathrm{C} 1$. These findings are similar to those reported by others (Halliday and McLachlan, 1991). For the unilateral VLM lesion group comparisons were carried out between the lesioned and nonlesioned sides and between the nonlesioned side of lesioned animals and the comesponding side in intact animals, using paired and unpaired $t$ tests, respectively. For the blood pressure recordings the average mean arterial pressures for the prehypoxia and hypoxia periods were compared for each animal using paired $t$ tests.

\section{Results}

Controls. In control animals the SON and PVN of hypothalamus, and the VLM, were virtually devoid of FLI (Fig. 1). Catecholamine cells of the dorsal medulla and the pons showed a similar lack of activity. Animals with unilateral VLM lesions but otherwise treated identically to control animals, also displayed negligible FLI in these areas.

Hypoxia-intact. In SON, significant activation was first apparent at the $10 \% \mathrm{O}_{2}$ level of hypoxia for both OT and VP neurosecretory cell types (Figs. 1,2). More severe levels of hyp-

$B$, OT and Fos; $C$, VP and Fos. In SON FLI was predominantly located in VP neurosecretory cells. PVN: $A$, immunolabeled for $O{ }^{\prime}$ and Fos; $B$, OT and Fos; $C$, VP and Fos. Most PVN FLI was located in the medial parvocellular (MP) zone in a distribution that corresponds to the that of CRF-containing cells $(B)$, but neurosecretory cell activation was also evident $(C)$. VLM $(A-C)$ : immunolabeled for TH and Fos. VLM catecholamine cell c-fos expression is depicted at two rostro-caudal levels: caudal VLM $(-1.0 \mathrm{~mm}$ relative to obex; $B)$ and rostral VLM $(+1.0 \mathrm{~mm} ; C)$. Note that most of the FLI is colocalized with TH positive cells. Scale bars: $50 \mu \mathrm{m}$ [SON, PVN $(C), \mathrm{VLM}$ ]; $100 \mu \mathrm{m}(\mathrm{PVN} A, B)$. 


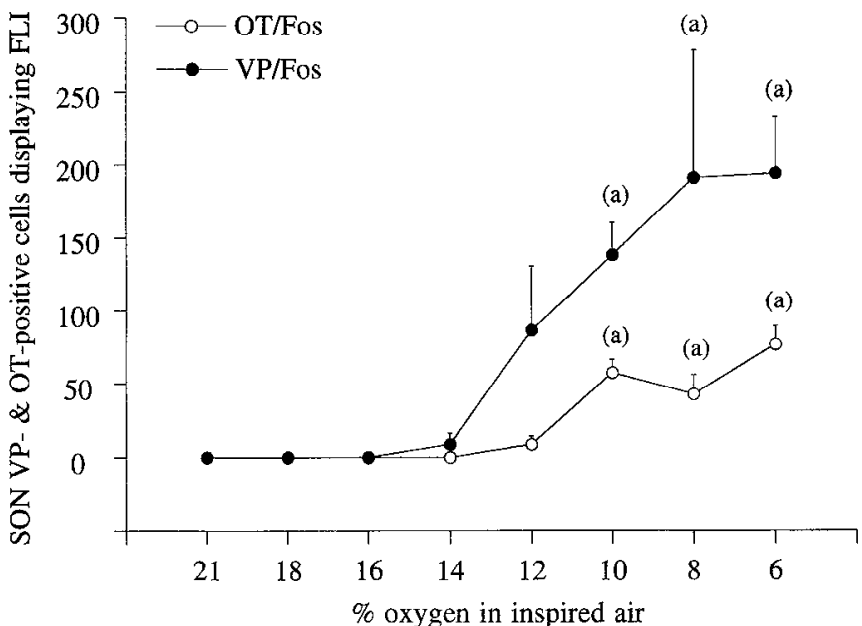

Figure 2. Effects of graded systemic hypoxia on c-fos expression in SON neurosecretory cells. Threshold level for c-fos expression was at $10 \%$ level of hypoxia for both neurosecretory cell types. At greater levels of hypoxia there was no further increase in the number of VP or OT cells colocalizing FLI. For all graphs of this type, significant differences are indicated as: $a=$ significantly greater than $21 \% ; b=$ significantly greater than $12 \% ; c=$ significantly greater than $10 \% ; d=$ significantly greater than $8 \%$. All are at least at the $p<0.05$ level.

oxia ( 8 and $6 \% \mathrm{O}_{2}$ ) did not elicit a greater degree of VP or OT cell activation than that observed at the $10 \% \mathrm{O}_{2}$ level. In PVN, significant activation of OT and VP magnocellular and MP region cells also tirst occurred at the $10 \% \mathrm{O}_{2}$ level of hypoxia (Figs. 1, 3). At more hypoxic levels only the VP and MP cells showed significantly greater lcvels of activation $(p<0.01)$. The majority of MP region FLI was localized in the dorsal and dorsolateral regions (see Fig. 1, $P V N B$ ), a distribution very similar to that previously shown for CRF-containing cells (Swanson et al., 1983). A relatively minor contribution from the ventral MP region (putative autonomic related cells.) was apparent.

Considering the VLM as a whole, significant activation of catecholaminergic cells first occurred at the $12 \% \mathrm{O}_{2}$ level of hypoxia (Figs. 1, 4). Further increases in the level of hypoxia caused markedly greater levels of VLM catecholamine cell activation, with 10,8 , and $6 \%$ levels resulting in significantly more activation than $12 \%$, and $6 \%$ resulting in significantly more activation than $10 \%$.

Analysis of activation of catecholamine cells through the rostro-caudal extent of the VLM suggested a distinct recruitment pattern (Fig. 5). At the $12 \% \mathrm{O}_{2}$ level of hypoxia there was significant catecholamine cell activation within the $\Lambda 1 / \mathrm{Cl}$ and $\mathrm{C} 1$ zones $(p<0.01)$ but not the Al zone. This activation was maximal at the level of obex. At the $10 \% \mathrm{O}_{2}$ level of hypoxia all three zones showed significantly greater levels of activation than at the $12 \%$ level $(p<0.01)$, with the greatest increase apparent in the A1 zone. There was a significantly higher level of activation in the Al zone of animals exposed to $6 \%$ hypoxic gas mixtures compared to $10 \%(p<0.05)$.

Animals subjected to hypoxia also showed apparent increases in FLI in catecholamine cells of the A5 and A6 (but not subA6) groups. This activation was especially evident in the $6 \%$ group as was an area postrema activation. The $\mathrm{A} 2 / \mathrm{C} 2$ catecholamine groups of the dorsal medulla also showed substantial colocalization of FLI. Although this response was not quantified it was readily apparent compared to controls and was centred at the level of obex. Particularly numerous and intensely FLI nuclei

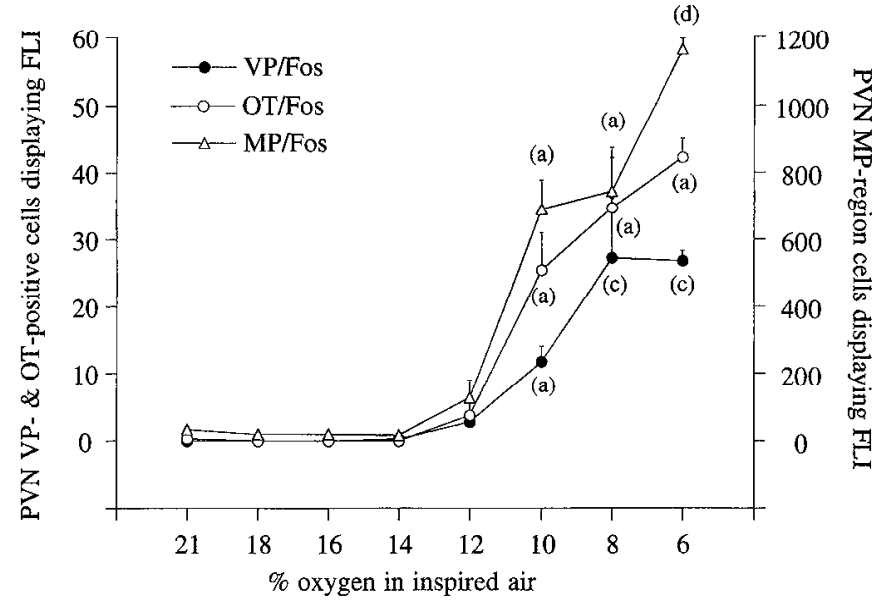

Figure 3. Effects of graded systemic hypoxia on c-fos expression in PVN neurosecretory and putative CRF cells. As in the SON, the threshold for cell activation was at the $10 \%$ level. In contrast to the SON, the OT response was numerically greater than the VP response. See Figure 2 caption for explanation of the significant differences.

were apparent in the commissural and medial subdivisions of the NTS and in more rostral NTS regions.

Hypoxia-AI sham lesions. VP, OT, PVN MP, and A1 cell c-fos expression in sham lesioned animals exposed to $10 \% \mathrm{O}_{2}$ was not significantly different to that observed in the intact $10 \%$ $\mathrm{O}_{2}$ hypoxia group. Consequently, data from this group was not analyzed further.

Hypoxia-Al lesions. Ibotenic acid markedly reduced the number of VLM TH-positive cell bodies on the side of the injection (Figs. 6, 7A). The lesion, as determined by significant reduction in $\mathrm{TH}$-positive cell counts on the lesioned side, extended from $2.5 \mathrm{~mm}$ caudal to $0.5 \mathrm{~mm}$ rostral to obex (Fig. 7A).

In SON of lesioned animals $10 \%$ hypoxia still elicited increases in FLI in O'T and VP cells, but there was significanIt sidedness to this effect with the side ipsilateral to the lesion having approximately $70 \%$ and $50 \%$ less OT-FLI and VP-FLI respectively than the contralateral side (Figs. 6, 7B). In PVN of lesioned

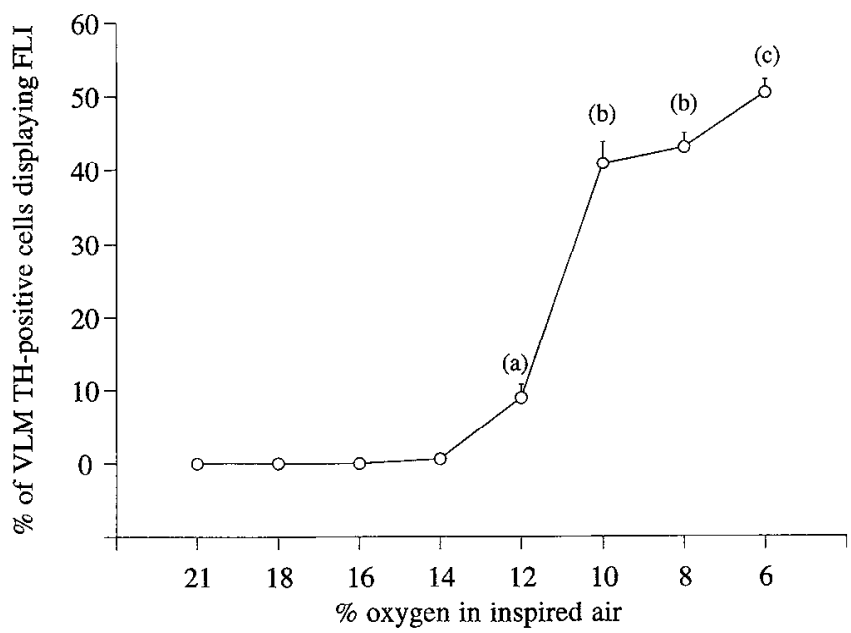

Figure 4. Effects of graded systemic hypoxia on c-fos expression in VLM catecholamine cells. Although there was significant FLI colocalization in TH positive cells at the $12 \%$ level, the effect was markedly more robust at $10 \%$ and lower levels. Percentages are averages for the VLM considered as a whole. See Figure 2 caption for explanation of the significant differences. 


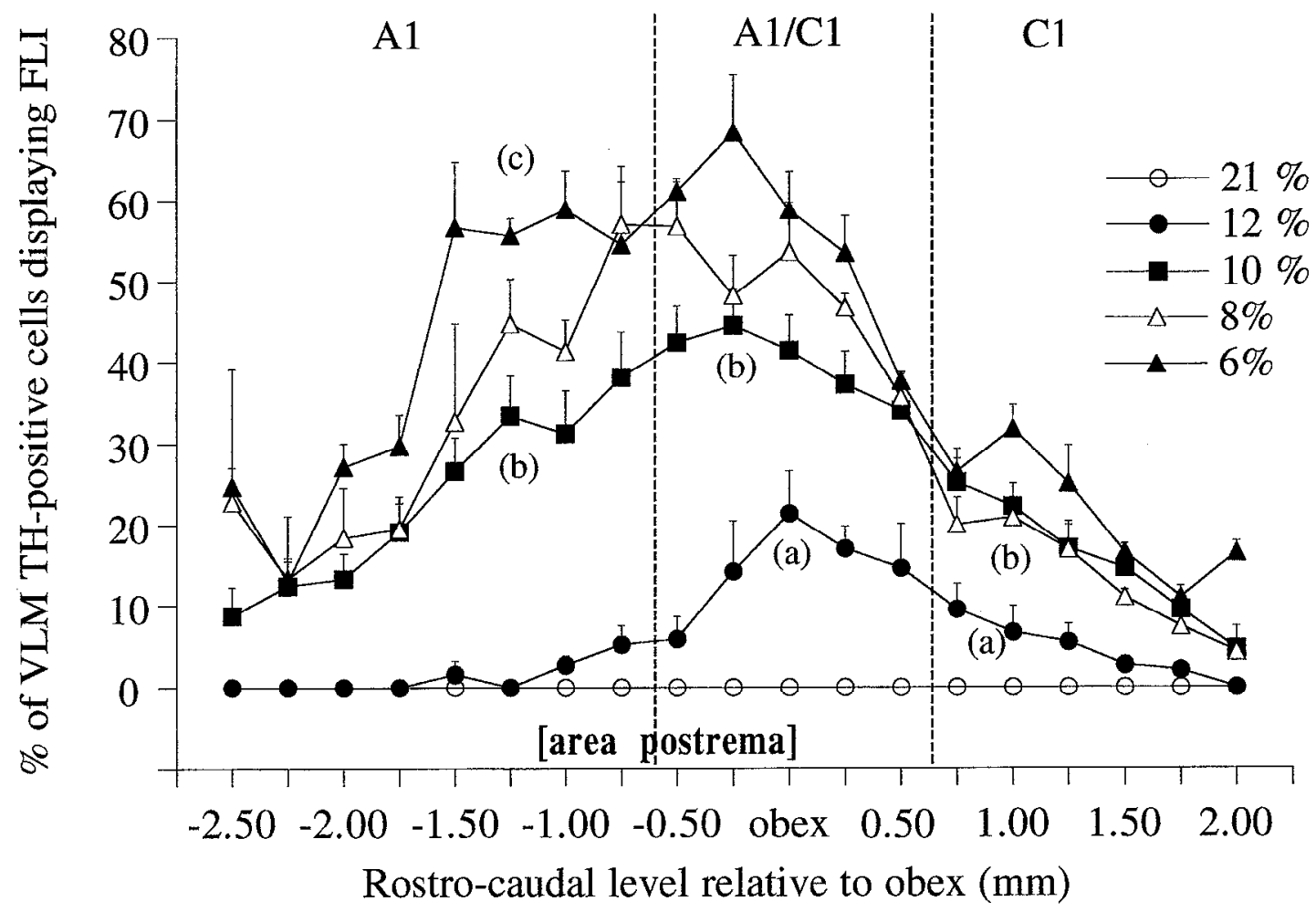

Figure 5. Effects of graded systemic hypoxia on c-fos expression in VLM catecholamine cells at different rostro-caudal levels. Cell group boundaries were determined from a separate quantitative TH versus PNMT immunolabeling study (see Materials and Methods). Note that at the $12 \%$ level of hypoxia most of the activated cells were centred around obex whereas at more severe hypoxic levels there was a caudal shift such that the majority of activated cells were at levels adjacent to and including those corresponding to the area postrema. The 6\% level was particularly effective at activating caudal Al zone cells. See Figure 2 caption for explanation of the significant differences.

animals there was also a distinct sidedness in the response to hypoxia, with the side ipsilateral to the lesion having significantly less OT-, VP-, and MP-FLI than the side contralateral to the lesion (Figs. 6, 7C,D).

Comparison of responses between the nonlesioned side of lesioned animals and the corresponding side of intact animals revealed that the MP region response in lesioned animals was significantly smaller than that in intact animals, the response being approximately $40 \%$ of that found in intact animals $(p<$ $0.001)$. Responses of nonlesioned side A1, VP and OT cells were not different to those in the intact animal.

Hypoxia-blood pressure. Animals subjected to either 10, 8, or $6 \%$ hypoxia did not show any significant changes in blood pressure from their prehypoxia values (Fig. 8).

\section{Discussion}

The findings of the present study are significant in at least three major aspects. Firstly, and importantly, it provides the first direct evidence of a role for VLM catecholamine cells in the generalion of neuroendocrine responses to systemic hypoxia. Secondly, they demonstrate a previously unsuspected pattern of recruitment along the rostro-caudal axis of the VI.M catecholamine cell column. Thirdly, they demonstrate a previously unreported response of OT cells to systemic hypoxia.

Neuroendocrine cell responses to hypoxia. Systemic hypoxia significantly increased c-fos expression in neurosecretory VP and OT cells of both SON and PVN, and also in medial parvocellular PVN cells, most of which are presumed to be CRF cells. Interestingly, all three cell populations were activated in parallel, displaying the same threshold for significant c-fos ex- pression. These findings are consistent with the known VP and ACTH responses to acute systemic hypoxia (Forsling and Aziz, 1983; Raff and Fagin, 1984; Raff, 1988; Griffen and Raff, 1990). The small yet significant increase in c-fos cxpression in OT cells of both SON and PVN however, was unexpected. In electrophysiological studies Harris (1979) found relatively insignificant SON OT cell responses to arterial chemoreceptor activation but it is notable that those studies involved relatively brief stimuli and anesthetized animals. The functional significance of the OT cell activation reported here is unclear, although it is perhaps relevant that OT is generally regarded as a stress hormone in rat (Lang et al., 1983). Whether OT is actually released into the blood in response to hypoxia is uncertain and it is of interest to note that Roberts et al. (1993) observed hemorrhageinduced SON OT cell c-fos expression even in the absence of increases in plasma OT.

The observation of a substantial PVN response to hypoxia stands in contrast to a previous report, based on electrophysiological studies, that PVN cells are unresponsive to arterial chemoreceptor stimulation (Banks and Harris, 1988). 'The use of brief stimuli under conditions of anesthesia may again be a significant factor here, as suggested above in relation to OT cell responses. With respect to the PVN CRF cell activation it is certainly notable that Raff (1988) found a significant increase in plasma ACTH $20 \mathrm{~min}$ but not $10 \mathrm{~min}$ after initiation of hypoxia, suggesting the need for a sustained stimulus in order to elicit ACTH secretion and, by implication, CRF cell activation.

Medullary cell responses to hypoxia. In NTS, systemic hypoxia induced c-fos expression within the commissural and medial subdivisions, a pattern consistent with that of the afferent 

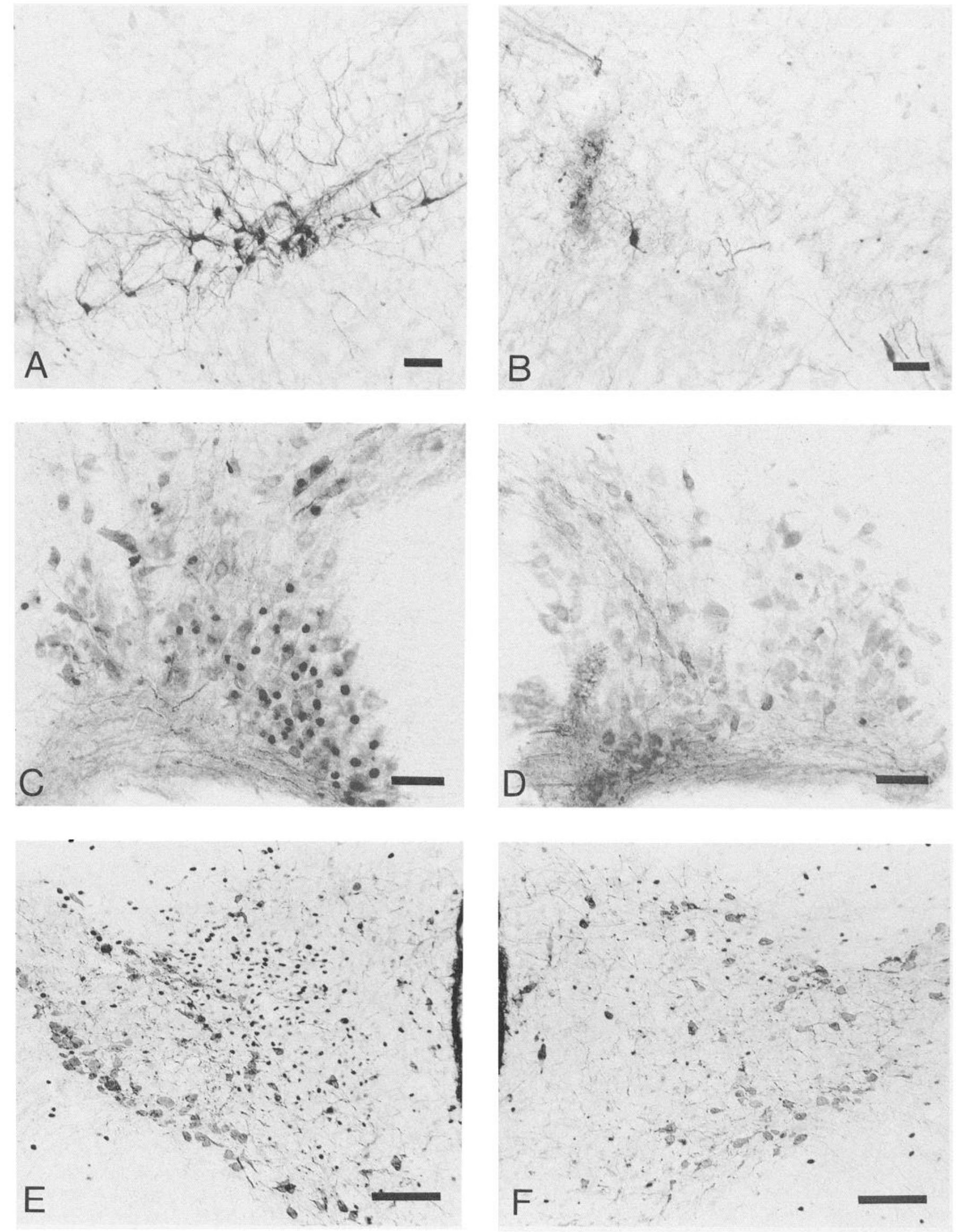

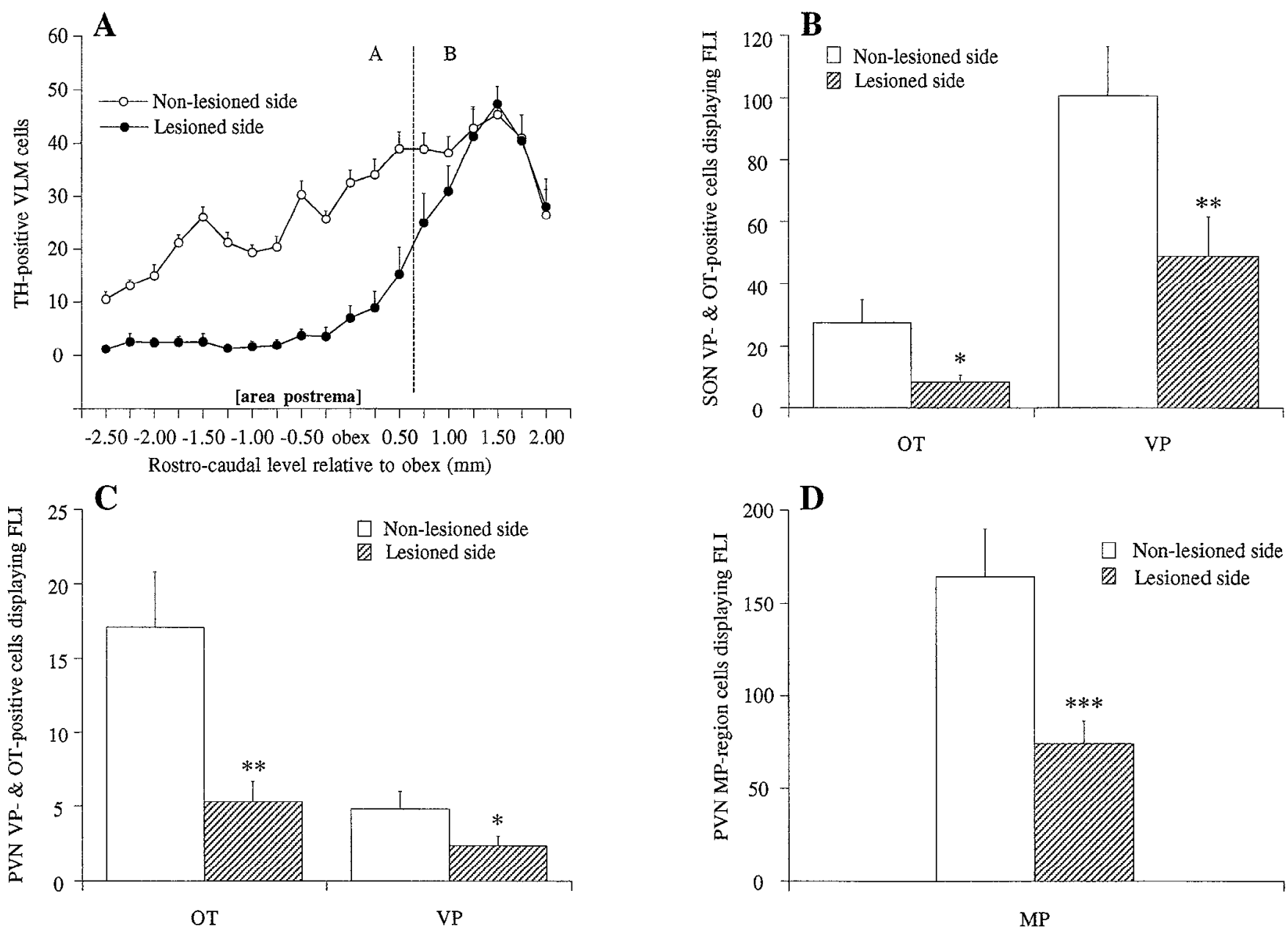

Figure 7. Effects of unilateral VLM lesions on: $(A)$ VLM catecholamine cells. On the lesioned side there was a significant reduction in the number of TH-positive cells compared to the nonlesioned side at all rostro-caudal levels on side of the dashed line labeled $A$. On the $B$ side there was no difference between the two sides. $B$, SON neurosecretory cells. Numbers of both VP and OT cells that colocalized FLI were significantly reduced on the side ipsilateral to the lesion. $C$, PVN neurosecretory cells. As in the SON, lesions ipsilaterally reduced VP and OT responses. $D$, PVN medial parvocellular cells. Lesions had a bilateral effect, however the effect on the ipsilateral side was more pronounced. ${ }^{*}, p<0.05 ; * *, p<$ $0.01 ; * * *, p<0.001$.

input to NTS from the carotid body (Finlay and Katz, 1992) and with a recent c-fos study that investigated medullary responses to hypoxia and carotid sinus nerve stimulation (Erickson and Millhorn, 1991, 1994). We also found substantial c-fos expression in catecholamine cells of NTS which are known to project to the PVN and, to a lesser extent, the SON (Swanson et al., 1983; Cunningham and Sawchenko, 1988; Cunningham et al., 1990). It is certainly possible that these NTS catecholamine cells contribute to the neuroendocrine cell responses reported in the present study.

Systemic hypoxia activated a substantial proportion of VLM catecholamine cells. Although an electrophysiological study in rat failed to locate VLM cells that responded to carotid body chemoreceptor stimulation (Jamieson and Harris, 1989), similar studies in cat and rabbit did identify putative catecholamine cells of the VLM which were excited by carotid sinus nerve stimulation and acute systemic hypoxia, respectively (Ciriello and Caverson, 1984; Li et al., 1992).. Moreover, the present findings are consistent with a recent report by Erickson and Millhorn (1994), although in that study the effects of graded hypoxia were not examined. This feature of the present study has yielded interesting information concerning the pattern of VLM catecholamine cell recruitment. The threshold for VLM catecholamine cell group activation occurred at the $12 \% \mathrm{O}_{2}$ level of hypoxia, indicating greater sensitivity to the stimulus than displayed by neuroendocrine cells. At this level of hypoxia most activated catecholamine cells were centered around the level of obex, the majority being situated rostral to it. At $10 \% \mathrm{O}_{2}$ there was an

$\leftarrow$

Figure 6. Photomicrographs illustrating the effects of unilateral VLM lesions on: VLM TH immunostaining. $A$ depicts the nonlesioned (animal's left) side; a number of TH-positive cell bodies are apparent, some of which colocalize FLI. $B$ depicts the lesioned side (contralateral side of same section as in $A$ ); ibotenic acid ablated the majority of VLM catecholamine cells in the region of the injections; sections at approximately 1.0 mm caudal to obex. $C$ and $D$, SON VP cell c-fos expression. $E$ and $F$, PVN OT cell and MP region c-fos expression. The left column $(A, C$, $E$ ) represents the side contralateral and the right column $(B, D, F)$ represents the side ipsilateral to the lesion. In all cases the micrographs are of opposite sides from the same sections. Note the substantial reduction in neuroendocrine cell responses on the side ipsilateral to the lesion. In the case of MP cells the effect was bilateral. Scale bar, $100 \mu \mathrm{m}(A, B, E, F) ; 50 \mu \mathrm{m}(C, D)$. 


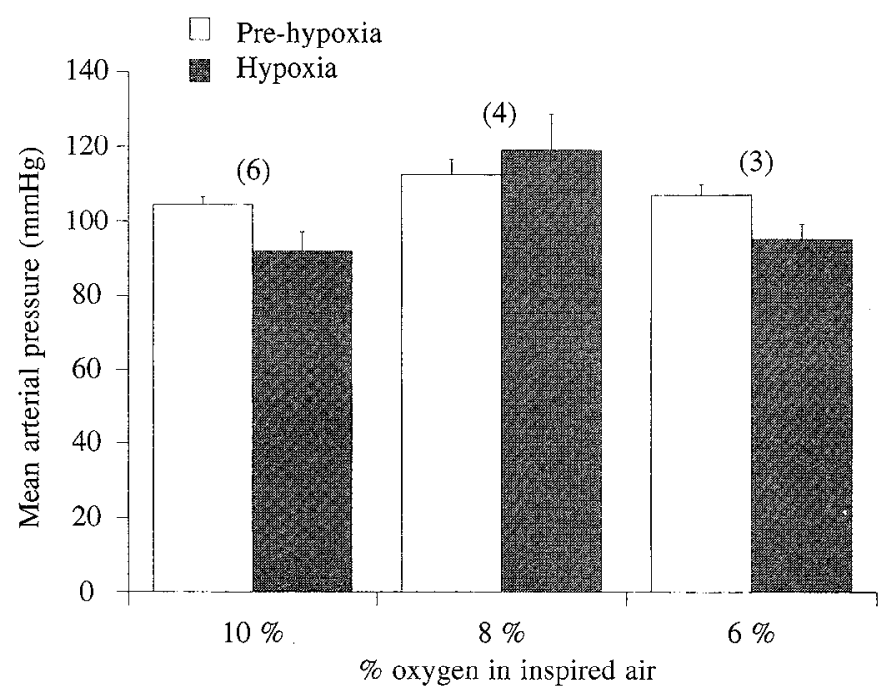

Figure 8. Effects of systemic hypoxia at either 10,8 , or $6 \%$ on mean arterial pressure. Although small inconsistent trends were apparent no significant differences were found at any level evaluated. The prehypoxia values were taken over a 1 hr period, the hypoxia values over the first $1.5 \mathrm{hr}$ of hypoxic stimulation.

increase in the percentage of activated cells at all rostro-caudal levels. At more hypoxic levels only caudal VLM cells showed significant further increases in recruitment. Given the distribution of Al and Cl cells in the VLM (Armstrong et al., 1982; Kalia et al., 1985) this suggests that the recruitment pattern shifts as inspirate oxygen levels fall, with the Al group becoming increasingly activated while $\mathrm{Cl}$ group involvement remains static. This finding has possible functional implications in relation to neuroendocrine control. Thus, whereas SON cell responses plateaud at the $10 \% \mathrm{O}_{2}$ level of hypoxia, in PVN further increases in VP and MP cell responses were observed at the $6 \% \mathrm{O}_{2}$ level of hypoxia. Notably, in absolute terms the magnitude of the PVN MP cell response was much greater than that of the PVN VP cell population. It appcars, therefore, that PVN ncuroendocrine cells, especially putative CRF-containing ones, continue to be recruited progressively even, or especially, in circumstances of severe homeostatic perturbation, and that caudal A1 cells might be involved in this recruitment.

Role of caudal VLM catecholamine cells in neuroendocrine cell responses to hypoxia. Ibotenic acid lesions of the VLM significantly reduced the responses of all three neuroendocrine cell types to hypoxia. This effect is assumed to be due to the destruction of VLM catecholamine cells and analysis of TH immunostaining in lesioned animals demonstrated that lesions were predominantly restricted to a region corresponding to the $\mathrm{Al}$ and caudal C1 cell groups (Armstrong et al., 1982; Kalia et al., 1985). However, as ibotenic acid is a nonspecific excitotoxin to cell bodies (Winn et al., 1984), it is conceivable that this effect could, at least in part, be due to destruction of noncatecholaminergic VLM cells. Indeed, a small number of noncatecholaminergic VLM cells were found to be activated by hypoxia in intact animals. Two lines of evidence suggest that it is catecholaminergic VLM cells that are critical to the observed neuroendocrine responses. Firstly, tracing studies have shown that the vast majority $(\geq 90 \%)$ of direct SON- or PVN-projecting VLM cells are catecholaminergic (Sawchenko and Swanson, 1982b). Secondly, electrophysiological data suggests that an indirect input from VLM cells to neuroendocrine cells is unlikely given that the effects of VLM stimulation on SON and PVN cells are all unimodal and, importantly, are abolished by destruction of hypothalamic catecholamine afferents (see Discussion in Day et al., 1992). Another mechanism by which VLM lesions might, theoretically, alter neuroendocrine responses to hypoxia is via an impaired ventilatory response stemming from effects on the ventral respiratory group (Ellenberger et al., 1990). This seems improbable, however, as A1, VP, and OT cell responses on the nonlesioned side of lesioned animals were not significantly different from corresponding cell population responses in intact animals. It is notable that the MP zone response on the nonlesioned side was markedly reduced, but this may reflect a difference in the degree to which Al cells regulating CRF cells project bilaterally compared to those regulating neurosecretory cells.

With respect to the altered OT cell response, these findings are somewhat surprising in that they suggest a role for VLM catecholamine cells in the activation of neurosecretory OT cells. This stands in marked contrast to previous data. Thus, anatomical studies have shown that Al fibres preferentially terminate in the magnocellular VP containing regions of both SON and PVN (Sawchenko and Swanson, 1982b; Cunningham and Sawchenko, 1988) and $\mathrm{Cl}$ fibers terminate mainly in PVN parvocellular regions (Cunningham et al., 1990). Moreover, electrophysiological studies have shown that stimulation of the VLM excites VP but not OT magnocellular cells (Day and Renaud, 1984; Day et al., 1984). However, with respect to the anatomical evidence, it is now well known that the dendritic trees of neurosecretory cells arborize extensively, while with regard to the functional evidence it is conceivable that a mild activation, not detected through conventional extracellular electrophysiological analysis, could induce c-fos expression when applied over an extended period of time. The findings of the anatomical tracing studies cited above would also suggest that the Al cell group does not play a role in regulation of putative CRF cells. However, the parallel activation of caudal VLM catecholamine and PVN MP cells and the effects of caudal VLM lesions on MP cell responses to systemic hypoxia suggest that the Al cell group does have a role in CRF cell regulation. In support of this contention electrical stimulation of caudal VLM at levels where C1 adrenergic cells would not be expected have been reported to enhance the firing of median eminence-projecting PVN MP cells (Day et al., 1985).

A number of stimuli, including hypovolaemia, hypotension, and increased plasma osmolality, as well as humoral factors such as angiotensin II, are all known to be potent augmentors of neuroendocrine cell activity (Shen et al., 1992; Fenelon et al., 1993; Roberts et al., 1993; Zardetto-Smith et al., 1993; Rowland et al., 1994). Thus, a consideration of the present study was whether the neuroendocrine and VLM catecholamine cell responses observed resulted from secondary effects of systemic hypoxia or from hypoxia per se. The levels of hypoxia used in the present study do not appear to have significant effects on systemic blood volume as indicated by previous reports demonstrating no change in haematocrit at various severities of systemic hypoxia (Altland et al., 1967; Raff, 1988). Previous reports also indicate no effect on plasma osmolality or renin activity (Forsling and Aziz, 1983; Raff, 1988; Griffen and Raff, 1990), the latter suggesting that the renin-angiotensin system is not involved in the neuroendocrine responses to systemic hypoxia. Whether systemic hypoxia causes hypotension is cquivocal. Some studics have reported falls in arterial pressure, although these have been rel- 
atively small (10-20 mmHg) and variable in size (Walker, 1986; Marshall and Metcalfe, 1990), whereas others have reported no effect and sometimes an increase (Forsling and Aziz, 1983; Raff and Roarty, 1988; Griffen and Raff, 1990). Results from the present study suggest that a significant change in blood pressure does not occur at any of the suprathreshold levels of hypoxia. Moreover, it is notable that hypotension, to a level much greater than has been reported by some studies to result from systemic hypoxia (see above), is an ineffective stimulus for c-fos expression in Al cells (Chan and Sawchenko, 1994). Therefore, taken together, these findings suggest that the neuroendocrine responses to systemic hypoxia in the present study are largely, if not entirely, due to hypoxia and not some other secondary effect.

In summary, our results suggest that VP, OT, and ACTH neuroendocrine responses to systemic hypoxia are at least partially mediated by catecholamine cells of the VLM. In relation to the role of the two VLM catecholamine cell groups in these responses, the pattern of recruitment and the effects of caudal VLM lesions suggests that the Al noradrenergic and not the Cl adrenergic cell group is the primary contributor to all three neuroendocrine cell responses, although a minor contribution from the $\mathrm{Cl}$ group cannot be ruled out. While a role for the Al cell group in VP cell regulation is well established the present data also suggest a role for this group in both OT and putative CRF cell regulation, findings which go against current consensus. Thus, previous neuroanatomical findings indicate that the SON and PVN OT regions and the PVN MP region are not innervated to any great extent by A1 noradrenergic fibres. The discrepancies between the current functional and previous anatomical findings may be indicative of some of the difficulties in ascribing function from purely anatomical data.

\section{References}

Altland PD, Brubach HF, Parker MG, Highman B (1967) Blood gases and acid-base values of unanesthetized rats exposed to hypoxia. Am J Physiol 212:142-148.

Armstrong DM, Ross CA, Pickel VM, Joh TH, Reis DJ (1982) Distribution of dopaminc-, noradrenalinc-, and adrenalinc- containing cell bodies in the rat medulla oblongata: demonstrated by the immunocytochemical localization of catecholamine biosynthetic enzymes. J Comp Neurol 212:173-187.

Banks D, Harris MC (1984) Lesions of the locus coeruleus abolish baroreceptor-induced depression of supraoptic neurones in the rat. $\mathbf{J}$ Physiol (Lond) 355:383-398.

Banks D, Harris M C (1988) Activation of hypothalamic arcuate but not paraventricular neurons following carotid body chemoreceptor stimulation in the rat. Neuroscience 24:967-976.

Chan RKW, Sawchenko PE (1994) Spatially and temporally differentiated patterns of c-fos expression in brainstem catecholaminergic cell groups induced by cardiovascular challenges in the rat. J Comp Neurol 348:433-460.

Ciriello J, Caverson MM (1984) Ventrolateral medullary neurons relay cardiovascular inputs to the paraventricular nucleus. Am J Physiol 246:R968-R978.

Cunningham E'I; Sawchenko PE (1988) Anatomical specificity of noradrenergic inputs to the paraventricular and supraoptic nuclei of the rat hypothalamus. J Comp Neurol 274:60-76.

Cunningham ET, Bohn MC, Sawchenko PE (1990) Organization of adrenergic inputs to the paraventricular and supraoptic nuclei of the hypothalamus in the rat. J Comp Neurol 292:651-66-7.

Day TA, Renaud LP (1984) Electrophysiological evidence that noradrenergic afferents selectively facilitate the activity of supraoptic vasopressin neurons. Brain Res 303:233-240.

Day TA, Sibbald JR (1989) Al cell group mediates solitary nucleus excitation of supraoptic vasopressin cells. Am J Physiol 257:R1020R1026.

Day TA, Ferguson AV, Renaud LP (1984) Facilitatory influence of noradrenergic afferents on the excitability of rat paraventricular nucleus neurosecretory cells. J Physiol (Lond) 355:237-249.

Day TA, Ferguson AV, Renaud LP (1985) Noradrenergic afferents facilitate the activity of tuberoinfundibular neurons of the hypothalamic paraventricular nucleus. Neuroendocrinology 41:17-22.

Day TA, Sibbald JR, Smith DW (1992) A1 neurons and excitatory amino acid receptors in rat caudal medulla mediate vagal excitation of supraoptic vasopressin cells. Brain Res 594:244-252.

Ellenberger HH, Feldman JL, Zhan W-Z (1990) Subnuclear organization of the lateral tegmental field of the rat. II. catecholamine neurons and ventral respiratory group. J Comp Neurol 294:212-222.

Erickson JT, Milthorn DE (1991) Fos-like protein is induced in neurons of the medulla oblongata after stimulation of the carotid sinus nerve in awake and anesthetized rats. Brain Res 567:11-24.

Erickson JT, Millhorn DE (1994) Hypoxia and electrical stimulation of the carotid sinus nerve induce Fos-like immunoreactivity within catecholaminergic and serotoninergic neurons of the rat brainstem. J Comp Neurol 348:161-182.

Fenelon VS, Poulain DA, Theodosis DT (1993) Oxytocin neuron activation and fos expression: a quantitative immunocytochemical analysis of the effect of lactation, parturition, osmotic and cardiovascular stimulation. Neuroscience 53:77-89.

Finlay JCW, Katz DM (1992) The central organization of carotid body afferent projections to the brainstem of the rat. Brain Res 572:108116.

Forsling ML, Aziz LA (1983) Release of vasopressin in response to hypoxia and the effect of aminergic and opioid antagonists. J Endocrinol 99:77-86.

Griffen SC, Raff H (1990) Vasopressin responses to hypoxia in conscious rats: interaction with water restriction. J Endocrinol 125:6166.

Halliday GM, McLachlan EM (1991) Four groups of tyrosine hydroxylase-immunoreactive neurons in the ventrolateral medulla of rats, guinea-pigs and cats identified on the basis of chemistry, topography and morphology. Neuroscience 43:551-568.

Hanley DF, Wilson DA, Feldman MA, Traystman RJ (1988) Peripheral chemoreceptor control of neurohypophysial blood flow. Am J Physiol 254:H742-H750.

Harris MC (1979) Effects of chemoreceptor and baroreceptor stimulation on the discharge of hypothalamic supraoptic neurones in rats. J Endocrinol 82:115-125.

Housley GD, Martin-Body RL, Dawson NJ, Sinclair JD (1987) Brain stem projections of the glossopharyngeal nerve and its carotid sinus branch in the rat. Neuroscience 22:237-250.

Jamieson SM, Harris MC (1989) Stimulation of carotid body chemoreceptors does not influence the discharge of $\mathrm{A} 1$ neurons projecting to the forebrain. Neuroscience 32:227-234.

Kalia M, Sullivan JM (1982) Brainstem projections of sensory and motor components of the vagus nerve in the rat. J Comp Neurol 211 : 248-264.

Kalia M, Fuxe K, Goldstein M (1985) Rat medulla oblongata II. Dopaminergic, noradrenergic (A1 and $\mathrm{A} 2$ ) and adrenergic neurons, nerve fibres, and presumptive terminal processes. J Comp Neurol 233:308-332.

Kannan H, Kasai M, Osaka T, Yamashita H (1987) Neurons in the paraventricular nucleus projecting to the median eminence: a study of their afferent connections from peripheral baroreceptors, and from the A1-catecholaminergic area in the ventrolateral medulla. Brain Res 409:358-363.

Kannan H, Yandashita H, Osaka T (1984) Paraventricular neurosecretory neurons: synaptic inputs from the ventrolateral medulla in rats. Neurosci Lett 51:183-188.

Lang RE, Heil JWE, Ganten D, Hermann K, Unger T, Rascher W (1983) Oxytocin unlike vasopressin is a stress hormone in the rat. Neuroendocrinology 37:314-316

Li YW, Gieroba ZJ, Blessing WW (1992) Chemoreceptor and baroreceptor responses of Al-area neurons projecting to supraoptic nucleus. Am J Physiol 263:R310-R317.

Louwerse A-M, Marshall JM, Forsling ML (1992) The role of vasopressin (AVP) in the cardiovascular response evoked by hypocapnicand normocapnic-hypoxia in the anacsthetized rat. J Physiol (Lond) 452:220P

Marshall JM, Metcalfe JD (1990) Effects of systemic hypoxia on the distribution of cardiac output in the rat. J Physiol (Lond) 426:335353. 
Morrison SF, Milner TA, Reis DJ (1988) Reticulospinal vasomotor neurons of the rat rostral ventrolateral medulla: relationship to sympathetic nerve activity and the $\mathrm{C} 1$ adrenergic cell group. J Neurosei $8: 1286-1301$.

Raff $\mathbf{H}$ (1988) Evaluation of a blood sample-transfusion protocol in rats: blood gases, renin, and ACTH. Am J Physiol 255:R851-R854.

Raff H, Fagin KD (1984) Measurement of hormones and blood gases during hypoxia in conscious cannulated rats. Am J Physiol 56:14261430.

Raff H, Roarty TP (1988) Renin, ACTH, and aldosterone during acute hypercapnia and hypoxia in conscious rats. Am J Physiol 254:R431R435.

Raff H, Shinsako J, Dallman MF (1984) Renin and ACTH responses to hypercapnia and hypoxia after chronic carotid chemodenervation. Am J Physiol 247:R412-R417.

Roberts MM, Robinson $\Lambda$ G, Fitzsimmons MD, Grant F, Lee W-S, Hoffman GE (1993) c-fos expression in vasopressin and oxytocin neurons reveals functional heterogeneity within magnocellular neurons. Neuroendocrinology 57:388-400.

Rowland NE, Li BH, Rozelle AK, Fregly MJ, Garcia M, Smith GC (1994) Localization of changes in immediate early genes in brain in relation to hydromineral balance: intravenous angiotensin II. Brain Res Bull 33:427-436.

Saphier D, Feldman S (1989) Catecholaminergic projections to tuberoinfundibular neurones of the paraventricular nucleus. II. Effects of stimulation of the ventral noradrenergic ascending bundle: evidence for cotransmission. Brain Res Bull 23:397-404.

Sawchenko PE, Swanson LW (1982a) Immunohistochemical identification of neurons in the paraventricular nucleus of the hypothalamus that project to the medulla or to the spinal cord in the rat. J Comp Neurol 205:260-272
Sawchenko PE, Swanson LW (1982b) The organisation of noradrenergic pathways from the brainstem to the paraventricular and supraoptic nuclei in the rat. Brain Res Rev 4:275-325.

Shen E, Dun SL, Ren C, Bennett-Clarke C, Dun NJ (1992) Hypotension preferentially induces c-fos immunoreacitivity in supraoptic vasopressin neurons. Brain Res 593:136-139.

Smith DW, Day TA (1993) Neurochemical identification of Fos-positive neurons using two-colour immunoperoxidase staining. J Neurosci Methods 47:73-83.

Swanson LW, Sawchenko PE, Rivier J, Vale WW (1983) Organization of ovine corticotropin-releasing factor immunoreactive cells and fibers in the rat brain: an immunohistochemical study. Neuroendocrinology 36:165-186.

Tanaka J, Kaba H, Saito H, Seto K (1984) The action of the A1 noradrenergic region on phasically firing neurons in the rat paraventricular nucleus. Brain Res 310:138-141.

Tucker DC, Saper CB, Ruggiero DA, Reis DJ (1987) Organization of central adrenergic pathways. I. Relationships of ventrolateral medullary projections to the hypothalamus and spinal cord. J Comp Neurol 259:591-603.

Walker BR (1986) Role of vasopressin in the cardiovascular response to hypoxia in the conscious rat. Am J Physiol 251:H1316-H1323.

Whitnall MH (1993) Regulation of the hypothalamic corticotropin-releasing hormone neurosecretory system. Prog Neurobiol 40:573-629.

Winn P, Tarbuck A, Dunnett SB (1984) Ibotenic acid lesions of the lateral hypothalamus: comparison with the electrolytic lesion syndrome. Neuroscience 12:225-240.

Zardetto-Smith AM, Thunhorst RL, Cicha MZ, Johnson AK (1993) Afferent signaling and forebrain mechanisms in the behavioral control of extracellular fluid volume. Ann NY Acad Sci 161-176. 